\title{
Salinity threat to Upper Egypt
}

SIR-Salinization of land in arid regions has led to a decrease in the fertility of soils in many areas of the world. In Egypt, salinization poses a threat to agricultural productivity as well as to the survival of many antiquities, mostly in irrigated land. Leaching of accumulated salts by annual inundations previously prevented land salinization in the Nile Valley, but that ceased when the Aswan High Dam was completed in $1965^{1,2}$. By 1977 , new salt deposits had been observed at the foundations of ancient monuments, but the reasons for the increase of groundwater salinity have been far from clear.

$$
\begin{gathered}
\mathrm{Na}^{+}+\mathrm{K}^{+} \text {concentrations and concentration ratios } \\
(1969-1987) \\
(\text { meq/L } \pm \text { s.d.) }
\end{gathered}
$$

\begin{tabular}{lclc}
\hline & Groundwater & Nile water & $\begin{array}{c}\text { Concentration } \\
\text { ratio }\end{array}$ \\
$1969-70$ & $9 \pm 2 *$ & $1.1 \pm 0.2$ & $8 \pm 2$ \\
1977 & $10.6 \pm 0.2$ & $1.52 \pm 0.03$ & $9 \pm 2$ \\
1987 & $10.2 \pm 0.7$ & $0.99 \pm 0.03$ & $9 \pm 2$ \\
Average & $10.0 \pm 0.7$ & $1.2 \pm 0.3$ & $9 \pm 1$
\end{tabular}

* Average of nine wells collected throughout Karnak ${ }^{3.4}$.
We selected the Karnak/ Luxor region for our studies because it is representative of archeological sites in Upper Egypt. It includes the Karnak Temple, one of Egypt's most important archaeological monuments, located between irrigated fields and the Nile River $^{1,2}$

Samples of groundwaters from the headquarters of the Canadian Archaeological Expedition immediately east of Karnak and of Nile water near Karnak were collected in 1977 and 1987, were analysed to determine $\mathrm{Na}^{+}$and $\mathrm{K}^{+}$concentrations using atomic absorption spectroscopy and were then compared with data assembled earlier ${ }^{3,4}$. It was determined that the concentrations of these ions in the Nile fluctuate within merely $\pm 25 \%$ over a period of eighteen years (see table). We have taken these ions as a proxy for salinity for that reason, because they are the most abundant ions in groundwater and because they are expected to be relatively unreactive with the soil. As an index of groundwater salinity, we took the ratio of the $\mathrm{Na}^{+}+\mathrm{K}^{+}$ concentration in the groundwater sample to the average concentration of these ions in the Nile River at Karnak. If these high concentrations of $\mathrm{Na}^{+}+\mathrm{K}^{+}$in 1969 were due to the previous inundation regime, they would have been leached out between 1969 and 1987. That there has been no such effect is not surprising: irrigation in Egypt has been stable for millennia.

Alternatively, high groundwater salinity could have arisen by the diffusion of salts in soils in the nearby desert, previously unaffected by irrigation, into agricultural areas. If such diffusion had been significant, a time-dependent concentration gradient would have been generated, but none has been observed.

1. Billard, T.C., \& Burns G. Nature 285, 654 - 655 (1980).

2. Billard, T.C. thesis, University of Toronto (1985)

3. Traunecker, C. Kermi 20, $213-228$ (1970)

4. Traunecker, C. Kêm/21, 177 - 196 (1971).

5. Pillsbury, A.F. Scient. Am. 55, 55 - 63 (1981). now used for irrigation evapotranspirates at the ground surface of the cultivated fields. This result is in itself remarkable. In the Colorado River Basin, for example, approximately only $75 \%$ of the water applied to irrigated fields is lost to evapotranspiration ${ }^{5}$. The climate of Upper
Egypt, situated between the Sahara and the Eastern deserts, is hotter and drier than in the Colorado Basin.

It therefore appears that evapotranspiration is an important process significantly contributing to the salinity of the groundwater in the Karnak area. Since $96 \%$ of the groundwater, which flows from the irrigated fields into the unirrigated land where the Karnak Temple Complex is located, evaporates under the temples ${ }^{2}$, practically all of the salts originally present in the irrigation waters are being deposited at the ground surface and, more devastatingly, in the foundations of the monuments at Karnak. Because irrigated fields are located along the Nile River over a large part of Egypt, we expect that the Nile Valley south of Fayum will be affected much as we have found the Karnak region to be.

G. BURNS

T.C. BILLARD

K.M. MATSUI

Department of Chemistry,

University of Toronto,

Toronto,

Ontario,

Canada M5S $1 A 1$

\section{Leaky answer to greenhouse gas?}

SIR - The British government is encouragingly positive towards action to reduce global warming from an increasing 'greenhouse' effect, using in particular arguments endorsed by the House of Commons Energy Committee ${ }^{1}$, that favour electricity generation from gas rather than coal. The case is based on the relative carbon coefficient of various fuels, essentially a measure of $\mathrm{CO}_{2}$ emission per unit of energy, and which are 0.75 for coal, 0.62 for oil and 0.43 for gas ${ }^{2}$. But does that argument hold up?

Methane makes up $75 \%$ of natural gas, has a stronger greenhouse effect than $\mathrm{CO}_{2}$ and its concentration in the atmosphere is increasing faster ${ }^{3}$. Because methane $\left(\mathrm{CH}_{4}\right)$ blocks radiation of wavelengths at which the atmosphere is relatively transparent, its 'greenhouse' strength per molecule is about 25 times stronger than that of $\mathrm{CO}_{2}$ (ref. 1). Releases of methane associated with coal mining and gas production may be significant ${ }^{4,5}$ relative to the biological production. The present increase of $1 \%$ per year (several times that for $\mathrm{CO}_{2}$ ) may reflect decreased $\mathrm{OH}$ density due to pollutants such as $\mathrm{CO}$, but in part reflects the increasing release rates.

The production and delivery of natural gas necessarily involves leakage - at the sea well-heads and high-pressure pumps (to 1,500 p.s.i.), at the shore hand-over and booster station, and in the local distribution net and beyond the meter. Gas leakage in the local net can be judged on the basis of the metered difference attributed as 'unaccounted for'. Through their recent substantial pipe-replacement works, British Gas has cut this from values that were as high as $15-20 \%$. The present 'unaccounted for' rate is $3-4 \%$ in Wales, little different from the UK average (J. Burrows, personal communication). British Gas told the Energy Committee that methane leakages from the gas grid amount to 400,000 tonnes per year, nearly $1 \%$ of throughput, but this is a politically motivated lower limit. Household gas meters are accurate to $\pm 2 \%$ so $I$ will assume $2-5 \%$ as a realistic range for leakage from the low-pressure delivery net. Leakage rates for sea-based production are unavailable, but $I$ estimate it to be $1-5 \%$, based on information from the Piper Alpha disaster inquiry. This estimate of $3-10 \%$ total losses is similar to the $3-6 \%$ derived for land-produced natural gas in the United States ${ }^{6}$, where there are legal restrictions and accounting for leakage.

Hence the relative greenhouse effects, correcting for the $3-10 \%$ leakage and expressed per carbon atom, are $G_{\text {gas }}: G_{\text {coal }}=$ $[0.43+\eta 0.75(0.03$ to 0.1$) \times 25]: 0.75=$ $0.57+(0.75$ to 2.5$) \eta$, where $\eta$ is the ratio of atmospheric residence times for $\mathrm{CH}$ and $\mathrm{CO}_{2}$. Evidently the value of $\eta$ is significant. The effective residence time for $\mathrm{CO}_{2}$ is uncertain, whereas that for the light $\mathrm{CH}_{4}$ is the stratospheric lifetime of 6.5 years (ref. 4) augmented by the upward diffusion time to a total of about 10 years. $\mathrm{CO}_{2}$ interchanges with oceans and biomass, a substantial fraction being 'fixed' as the annual atmospheric loading is only $50 \%$ of the global fossil-fuel burn. The 